\title{
Recurrent Chordoma
}

National Cancer Institute

\section{Source}

National Cancer Institute. Recurrent Chordoma. NCI Thesaurus. Code C155973.

The reemergence of chordoma after a period of remission. 